\title{
Cohabitation and commitment: partnership plans of young men and women
}

\author{
Lynn Jamieson, Michael Anderson, \\ David McCrone, Frank Bechhofer, \\ Robert Stewart and Yaojun Li
}

\begin{abstract}
Popular commentators on marriage and the family often interpret the increase in heterosexual couples living together without marrying as reduced willingness to create and honour life-long partnerships. Survey and in-depth interviews with samples of 20-29 year olds living in an urban area of Scotland finds little support for the postulated link between growing cohabitation and a weakened sense of commitment to long-term arrangements. Most of the cohabiting couples strongly stressed their 'commitment'. Socially acceptable vocabularies of motive undoubtedly influenced answers but interviews helped to explore deeper meanings. Many respondents' views were consistent with previous research predictions of a weakening sense of any added value of marriage. At the same time, some respondents continued to stress the social significance of the distinction between marriage and cohabitation, consistent with research interpreting cohabitation as a 'try and see' strategy part-way to the perceived full commitment of marriage. The notion that 'marriage is better for children' continued to have support among respondents. While, on average, cohabiting couples had lower incomes and poorer employment situations than married couples, only very extreme adverse circumstances were presented as making marriage 'too risky'. Pregnancy-provoked cohabitation was not always in this category. Cohabitation was maintained because marriage would 'make no difference' or because they 'had not yet got round to' marriage. Most respondents were more wary of attempting to schedule or plan in their personal life than in other domains and cohabitees' attitudes to partnership, including their generally 'committed' approach, do not explain the known greater vulnerability of this group to dissolution.
\end{abstract}

\section{Introduction}

Commentators on marriage and the family sometimes view pessimistically the increase in heterosexual couples living together without marrying as a reduction in willingness to create and honour life-long partnerships. High or rising 
rates of divorce and lone parenthood are seen as a similarly damning 'evidence'. However, sociological analysis has not unequivocally supported the postulated link between growing cohabitation and waning interest in life-long partnerships. As some European commentators have suggested, (Ermisch, 2000; Lewis, 1999a, 1999b, 2001; Manting, 1996; Prinz, 1995; Smart and Stevens, 2000) the empirical and theoretical basis for assuming that cohabitation without marriage means less commitment to long term couple relationships is rather equivocal.

It is worth noting that the current usage of the term 'commitment' to describe an intention to maintain a couple relationship over a long-time if not a life-time is rather historically-specific. It reflects social changes in everyday hopes for and expectations of couple relationships including a shift away from emphasis on traditional obligations as a husband/wife to emphasis on a more personally negotiated relationship. The everyday adoption of the term 'commitment' is as recent as the late twentieth century. Jane Lewis's study of couples from different generations notes: 'the notion of obligation was more readily accepted by the older generation and commitment by the younger' (1999b: 44). Many commentators argue that ideals concerning couple relationships, married or otherwise, have moved closer to what Giddens (1991, 1992) describes as the necessarily fragile 'pure relationship', the relationship that only lasts as long as it brings mutual benefit, even if the lived practical realities may be rather more complicated (Jamieson, 1998, 1999).

Christopher Prinz (1995) and Dorien Manting (1996) categorise changes in the meaning of cohabitation since the late twentieth century. Summarising change in partnership formation in the Netherlands over the decades since the 1950s, Manting suggests: 'Cohabitation started as an alternative way of living, developed into a temporary phase before marriage, and finally became a strategy for moving into a union gradually' (1996: 53). In making predictions concerning the future of cohabitation in the UK, Chris Shaw and John Haskey (1999), like Kiernan (1999) assume attitudes to cohabitation will move from 'being seen as a prelude to marriage to being an acceptable alternative to marriage' (1999: 13; Haskey, 2001). It is likely that what the authors mean here by 'alternative' is that couples will regard it as a matter of no consequence whether they get married or not as Prinz (1995) suggests, rather than 'alternative' in the stronger sense of alternative life-style used by Manting (1996). Jane Lewis has suggested that there is no longer any moral distinction between marriage and cohabitation for recent generations who believe "true morality has to come from within ... rather than from an externally prescribed moral code' and 'the kind of commitment a couple makes - public or private - is their own affair.' (2001: 145).

Social analysts sometimes present cohabitation as a bet-hedging strategy, a half-way house between full and no commitment. There is a suggestion that high hopes for 'a good relationship' encourage a process of weighing the quality of the relationship. Cohabiting allows more flexibility than marriage if one partner is not convinced that the quality is as good as s/he could hope 
for, and wishes to continue to weigh the relative benefits of being single, or living with another potential partner, against the experience of living with this partner (Kravdal, 1999: 66). So this is a trial not in the sense of 'Am I suited to being partnered in this way?' but 'Is this person good enough?' or 'the right one?' In this analysis, cohabitation is seen as having the advantage of easier exit, while, for its duration, search for alternatives is more or less suspended but not completely off the agenda. Ermisch's (2000) analysis of the British Household Panel Study suggests that, for this representative sample of the British population, cohabitation was mainly used as a trial marriage. He notes that most cohabitation either ended in marriage or people breaking up and trying again but the balance remains towards the former; more partners prove satisfactory than unsatisfactory. Smart and Stevens (2000) suggest that couples opt for cohabitation with little sense of any marriage prospects in circumstances, such as low incomes, poor employment prospects and unplanned parenthood, that are viewed as making marriage particularly 'risky'. (See footnote 5 for a description of income and employment in our own sample.)

The fact that there is no automatic association between cohabitation and absence of commitment has been demonstrated empirically for British cohabitants in a number of ways. Jane Lewis has conducted a qualitative study of two generations of relatively affluent long-term childrearing couples, exploring attitudes to marriage and cohabitation. She found that the meaning of cohabitation can change over time for some couples. For example, some couples in her sample had drifted into cohabitation for pragmatic reasons but by the time of interview saw their cohabitation as an expression of a private commitment to their relationship, a commitment that was, as one respondent put it, 'strong enough,' for them to decide to have children (Lewis, 1999b: 32-42). It is perhaps not surprising that commitment often grows in relationships that have survived over time. By the same token, a withering of commitment might be more common among relationships that fail. Carol Smart and Pippa Stevens conducted interviews with a small sample of parents who were ex-cohabitees in order to explore the causes of the breakdown of their relationship and the nature of their previous commitment to it. They found that even in this group a substantial proportion of cohabitees had begun their relationship with a strong sense of mutual commitment to staying together. Others always felt their commitment was contingent, usually on their relationship or their partner somehow getting better, and a few, exclusively men, had no sense of commitment but rather saw their cohabitation purely in terms of convenience.

This paper discusses the meaning of marriage, cohabitation and commitment for young adults in the age group 20-29 in the first year of the 21st century. It is possible for a couple to enter into cohabitation with different levels and understandings of commitment. They may view living together as the beginning of a permanent partnership. Alternatively they may see cohabitation as a way of testing out whether a permanent partnership is viable, bet- 
hedging as it has been described. Or, thirdly, they may drift into cohabitation with very little thought for the future, seeing it as a pragmatic arrangement that carries little or no burden of expectations. Each of these three ways of viewing the beginning of cohabitation, can be accompanied by positive, negative or fairly neutral views of marriage as an institution and as a possible future part of personal life. In the first two cases, cohabitation may be seen as part of a process of getting married or an equivalent path that is as-good-asmarried or an alternative that is better than marriage. It is also quite possible that each member of a couple will have a somewhat different view and that however they see their partnership at the outset, their views will change over time. Without ignoring this complexity, we attempt to capture the balance of typical ideals and behaviours among our 20-29 year old respondents. Which of the various optimistic and pessimistic academic visions of the future does this balance support?

\section{The data}

Our study ${ }^{1}$ is based on a sample of men and women aged 20-29. This is an ideal age group for an investigation of partnership practices and attitudes as it spans the modal age of cohabitation and first marriage. While this paper focuses on the coupled respondents, it draws on the single respondents to provide a more complete sense of the age group.

The sampling procedures aimed to find 200 randomly selected individuals in the age range 20-29 from within pre-specified postal districts in Fife, Scotland. ${ }^{2}$ The sample was stratified equally between the 20-24 and 25-29 age groups and between men and women. This resulted in an initial sample of 202 respondents within the age group, 93 living in couples, ${ }^{3}$ and 109 'singles', that is not living with a partner. Among the coupled respondents, we attempted to interview both partners and both were interviewed successfully in the majority of households. Most partners were also in the 20-29 age group. ${ }^{4}$ The result was data on 246 20-29 year olds, 109 single people and the remaining 137 drawn from 93 couples. Respondents in couples were almost equally divided between the married and the cohabiting, with higher rates of cohabitation in the early twenties and higher rates of marriage in the late twenties. ${ }^{5}$

In the survey, a structured questionnaire was used to ask a series of questions of couples that are relevant to their sense of commitment to each other in the past, present and future. Questions included their reasons for setting up home together and their plans at that time, their views in the present including their attitude to cohabitation versus marriage, and their plans for the future. Where appropriate, questions were drawn from existing household surveys such as the General Household Survey and the British Household Panel Survey. When possible, both partners of a couple were surveyed simultaneously by a single interviewer. Self-completion questions were used when the possibility of partners influencing each other's answers was not desired, 
or when the topic might force disclosure of sensitive information or initiate disagreement between couples.

As a follow-up to the survey, intensive interviews were conducted with 16 'single' people and 25 couples. The intensive couple interviews were largely conducted with couples in their late twenties, among whom the married predominate. Couples were interviewed together but in two cases one partner was absent for all or most of the interview. 17 intensive interviews were conducted with married couples, 12 had lived together before marriage and five had not. 12 of the married couples had children at the time of interview. Eight intensive interviews were conducted with cohabiting couples, seven of whom had children. ${ }^{6}$ All couples were interviewed by Robert Stewart. This paper draws on both the survey and these intensive interviews which are referred to by pseudonyms. ${ }^{7}$ The paper is organised by interweaving the survey data and material from the intensive interviews.

\section{Commitment from the beginning}

In the survey, all couples were asked 'When you and your current partner first decided to set up home or move in together, did you think of it as a permanent arrangement or something that you would try and then see how it worked?' This was one of a set of self-completion question followed up by asking about why they set up home together when they did. The majority of respondents, both men and women, described their arrangement as one that they thought of as permanent. However, the evidence suggests that a minority were using cohabitation in a bet hedging way. Overall, $80 \%$ said that their partnership was a permanent arrangement from the beginning and $20 \%$ said 'try and see'. The minority describing the arrangement in terms of 'try and see' was higher (30\%) among currently cohabiting respondents than among those who cohabited and then married (15\%). Also it was higher among younger cohabitees ( $38 \%$ of those under age 25$)$, than among older cohabitees (21\% of those of age 25 and over) and higher among younger men than younger women (43\% of cohabiting men age under 25 and $35 \%$ of cohabiting women aged under 25). The picture is further complicated if agreement between members of the couple is taken into account.

Table 1 shows that agreement between couples in describing the arrangement as permanent varied by partnership status. Only cases in which both partners answered are included. There were lower rates of agreement and lower proportions seeing it as a permanent arrangement among the cohabitees than among the married. The few couples who married without first living together all agreed that the arrangement was permanent. A clear majority of couples who cohabited then married agreed that it was permanent but $29 \%$ did not agree, although as individuals only 16\% thought in terms of 'try and see'. Among those currently cohabiting, as individuals 33\% thought of setting up home in terms of 'try and see' and the majority, two thirds, as a 
Table 1 Couples giving the same and different answers to: 'When you and your current partner first decided to set up home or move in together, did you think of it as a permanent arrangement or something that you would try and then see how it worked? ${ }^{8}$

\begin{tabular}{lccc}
\hline & $\begin{array}{c}\text { All cohabiting } \\
\text { without marriage }\end{array}$ & $\begin{array}{c}\text { Those who } \\
\text { cohabited and } \\
\text { then married }\end{array}$ & $\begin{array}{c}\text { Married without } \\
\text { cohabiting }\end{array}$ \\
\hline Both 'Permanent' & $48 \%$ & $67 \%$ & $100 \%$ \\
Both 'Try and see' & $13 \%$ & $4 \%$ & \\
Different answers & $39 \%$ & $29 \%$ & 9 \\
N $=100 \%$ & 31 & 24 & 9 \\
\hline
\end{tabular}

permanent arrangement, but less than half the couples agreed that their arrangement was permanent. 39\% did not agree and 13\% agreed it was a case of 'try and see'.

The cohabiting respondents who were particularly likely to describe the beginning of their partnership in terms of 'try and see' were younger respondents with children. In combination the survey data and the intensive interviews suggest that those who set up home together very young and who experienced an unexpected pregnancy at an early stage in their relationship were particularly likely to describe the beginning of their arrangement in terms of 'try and see'. These issues are explored further in the next section.

Some of the intensive interviews indicate that not all respondents drew a clear line between a permanent arrangement and 'try and see'. Lorraine and Craig Duncan were the youngest couple among our intensive interviews, at aged 22 and 23. They had been a couple since they were at school together and began living together as teenagers, first with parents and then in their own council house. They married at ages 19 and 20. In the survey, Lorraine described the point of setting up home together in terms of 'try and see' and Craig as 'permanent'. However, in interview Craig described how 'seeing if it would work' had been involved in the gap between asking Lorraine to marry him and getting married.

Craig: Aye it wis like the year before kinda, that wisnae like after when I first asked her or anything, it was like a year before the actual wedding date that we actually picked that date. So. Didnae ken why it was that long, like, but we just left it when I first asked her. Ken I suppose just in case we did ever split up or anything so we just left it to see if things would work out.

R.S.: Were you living together then?

Craig: Aye, so that was maybe part of it, seeing if it would work. 
Table 2 Percentage choosing each reason ${ }^{10}$ for setting up home when they did, by partnership status

\begin{tabular}{lccc}
\hline & $\begin{array}{c}\text { Never } \\
\text { married } \\
\text { cohabiting }\end{array}$ & $\begin{array}{c}\text { Married } \\
\text { after } \\
\text { cohabiting }\end{array}$ & $\begin{array}{c}\text { Married } \\
\text { never } \\
\text { cohabited }\end{array}$ \\
\hline $\begin{array}{l}\text { I wanted to commit myself to our } \\
\text { relationship }\end{array}$ & $72 \%$ & $63 \%$ & $54 \%$ \\
$\begin{array}{l}\text { We fell in love and could not live } \\
\text { without each other }\end{array}$ & $62 \%$ & $52 \%$ & $79 \%$ \\
$\begin{array}{l}\text { The time had come when I wanted } \\
\text { to live with a sexual partner }\end{array}$ & $27 \%$ & $44 \%$ & $17 \%$ \\
$\begin{array}{l}\text { I/my partner was pregnant } \\
\text { Rented accommodation became } \\
\text { available }\end{array}$ & $20 \%$ & $24 \%$ & $17 \%$ \\
$\begin{array}{l}\text { We'd got enough money together } \\
\text { to get a house }\end{array}$ & $15 \%$ & $35 \%$ & $8 \%$ \\
$\begin{array}{l}\text { I was at a suitable point in my } \\
\text { working life }\end{array}$ & $15 \%$ & $17 \%$ & $17 \%$ \\
$\begin{array}{l}\text { My partner was at a suitable point } \\
\text { in his/her working life }\end{array}$ & $13 \%$ & $9 \%$ & $29 \%$ \\
$\begin{array}{l}\text { Some other important factor } \\
\text { [N] = 100\% }\end{array}$ & $2 \%$ & $7 \%$ & $17 \%$ \\
\hline
\end{tabular}

The survey explored couples' reasons for setting up home together when they did, by offering a list of items that might have influenced them to do so and allowing respondents to choose as many as they wished. With the exception of 'the time had come when I wanted to live with a sexual partner', an answer more common among younger respondents, the pattern of responses did not vary markedly by age or gender but they did vary by partnership status. The differences are generally not sufficient to be statistically significant ${ }^{9}$ but the overall pattern of difference is nevertheless interesting. The results are shown in Table 2, by partnership history and status.

For respondents who were cohabiting without marriage, the most chosen item was 'I wanted to commit myself to our relationship', selected by over three quarters, followed by 'We fell in love and could not live without each other' chosen by over a half. While the pattern was similar for married respondents the order was reversed and 'We fell in love' was chosen by over three quarters and 'I wanted to commit myself to our relationship' by over a half. No other items commanded such support but a series of items referring to more pragmatic decisions and practical circumstances attracted the support of more than $20 \%$ of at least one of the three groups shown in the table: 'The time had come when I wanted to live with a sexual partner', '1/my partner 
was pregnant', 'rented accommodation became available', 'I was at a suitable point in my working life'. Those who had cohabited and then married more often chose 'the time had come to live with a sexual partner' and 'rented accommodation became available'. This may be more to do with acceptable vocabularies of motive than differences in behaviour. Unlike 'I was at a suitable point in my working life', these are not conventional good reasons for getting married and are chosen by very few of those who married without cohabiting. However, those who have made the transition from cohabitation to marriage can acknowledge these reasons for first setting up home together without suggesting any lack of substance to their relationship now. Cohabitees might feel that selecting such explanations carry greater risk of trivialising their relationship.

Over $40 \%$ of those surveyed chose both 'love' and 'commitment' among their reasons for setting up home together when they did. This was true, for example, of Mary Hutton and Bill Noble, both of whom we interviewed at length with their respective partners, cohabitees Greg Graham and Sharon Noble. Both couples now have children.

Mary Hutton was only 16 years old when she moved in with Greg who was then aged 23. On her survey she chose 'love', 'I wanted to live with a sexual partner' and 'I wanted to commit myself'. Greg chose 'I wanted to commit myself'. Both also indicated that they saw the arrangement as permanent at the time, although living together was not the result of a longstanding plan. Mary had been going out with Greg for three months when he asked her to move in with him. Mary explained that she asked her mother's permission: 'We were gonna leave it a wee while before we moved in. And, em, my mum was like, "Well, if you are moving in, you may as well do it this weekend", eh. So, that was that.'

Sharon and Bill Noble were aged 20 and 21 when they first met. Sharon was living with but in the process of 'breaking-up with' somebody else when she met Bill. Despite housing difficulties, they more or less started to live together very soon after first meeting. In the survey Bill is one of the larger minority among younger cohabitees who described the beginning of living together as 'try and see'. This couple are also among those who do not give the same answers as Sharon spoke of a 'permanent arrangement'. However, this is not a couple in disharmony. Both Bill and Sharon chose 'love' as a reason for setting up home together when they did but Bill also chose 'I wanted to commit myself'. This couple was effusive about being in love. Bill describes them as being 'daft about each other' and 'made for each other' and Sharon said 'when I met him, I knew that was him; he was the one.' As is discussed later, this couple discussed plans to marry from an early stage in their relationship, although they still had no definite date at the time of interview. 


\section{Beginning with an unplanned pregnancy}

Couples who set up home together because of an unplanned pregnancy have a distinct set of experiences that shed light on more general attitudes and approaches to cohabiting and marriage. The experience of an unplanned pregnancy focuses prospective parents on their views of the future of their relationship as a couple, bringing up children, cohabiting and marriage. About $25 \%$ of our respondents who were coupled with children reported a pregnancy as being an important influence in setting up home at that point in their life, rising to about a third among those who are still under 25 . The proportions were similar for married and cohabiting respondents. We conducted intensive interviews with respondents who were at different stages in their relationship when they experienced an unplanned pregnancy. Their accounts illustrate how reactions to unplanned pregnancy vary depending on whether a couple viewed themselves as established and committed or not. Some, who did not see themselves as either, at least not prior to that point, nevertheless chose to gamble on living together in a bet-hedging 'try and see' way. For those who saw themselves as already both established and committed, responding to the pregnancy simply speeded up anticipated aspects of consolidation as a couple.

Douglas Syme and Jean Taylor were a couple who had not even started to consider their future when Jean became pregnant. Both answered 'try and see' to the survey question. Jean was several years older than Douglas. She was legally separated from but still married to the father of her two older children. Very soon after their own son was born, Douglas moved in with Jean and her children. At the time of interview they had lived together for five years. Douglas speaking to the interviewer alone, explained,

I met my partner I'm wi' the now. I only knew her for five weeks before she fell pregnant. And I think it was just lucky that we were kinda in love, eh. And five years doon the line we're still together, so.

Douglas was keen to be a father. He stated that his commitment to Jean was reassessed as a result of his desire to be a good father. He wanted to prevent the reproduction of his own childhood feelings of being let down by an absentee father. This means staying with Jean.

Douglas: maybe if we never had a bairn, maybe, would me and Jean still be together? ... That's going through my mind 'cause I'm thinking, 'cause I remember saying to mysel', well I would never ever leave, split up 'cause I'd always stay wi' Jean for the child eh. Because maybe 'cause I never had that when I was young.

Our interviews also included couples who had already made a commitment to each other, in the sense of shared understanding of a long-term future 
together, before the accidental pregnancy. Joseph and Tracey Malcolm decided to get married when Tracey became pregnant. At that time, Tracey was aged 18 and Joseph aged 20. They had been engaged for a month and had a target wedding date in 15 months time. However, the date was brought forward a year in response to the pregnancy. At the time of interview, Tracey regretted this, not because she had any doubts about a commitment to Joseph or because she had reasons for preferring cohabitation to marriage but because she was not allowed to plan her wedding to her satisfaction. She felt that she missed out on her special day.

Tracey: If I look back on it now, I wouldn't have got married. I would've waited until after the pregnancy and got married. But because I was just young, I just went with the flow.

R.S.: Was there any pressure to do it?

Tracey: Aye. And plus we werenae paying for it, eh, it was my parents.

Joseph: There wis a lot of pressure, like, at the time, eh, but ...

Tracey: I do wish I could have my time back again and do it our own way. Have my own say in it. My own dress, my own everything. ... I didn't feel like I was important.

Although they themselves married, the Malcolms did not make a definitive distinction between marriage and cohabiting in terms of commitment. In the next section, examples are given of couples who were already living together and anticipating a long-term future together when they experienced an unexpected pregnancy. Such couples also did not typically emphasise a line between marriage and cohabitation in terms of less or more commitment. On the other hand, making a distinction between marriage and living together, emphasising the presumed easier exit from the latter, was important to some couples. They included some who were cautiously wishing to 'try and see' how living together worked out and some who wished to mark a transition in their relationship away from 'try and see' to a state of marriage that they defined as a more definite commitment.

\section{Views of cohabitation and marriage}

The survey included two questions about the relative advantages of marriage and cohabitation that were put to single people and cohabiting couples. ${ }^{12}$ First we asked if respondents thought there were any advantages in living together as a couple rather than being married. The second question simply reversed the position of 'living together as a couple' and 'being married'. The data indicate that the majority did not see one as clearly better than the other. Over half, $58 \%$, gave the same answer to both questions, that is they either thought that both living together and marriage have advantages over the other, or that neither has advantages over the other. ${ }^{13} 32 \%$ were prepared to declare one 
Table 3 Percentage of all single cohabiting and married respondents ${ }^{15}$ identifying advantages of particular living arrangements

\begin{tabular}{lccc}
\hline & Single & Cohabiting & Married \\
\hline $\begin{array}{l}\text { Yes advantages of living as a couple rather } \\
\quad \text { than being married }\end{array}$ & $60 \%$ & $34 \%$ & Not asked \\
No legal ties & $38 \%$ & $15 \%$ & $\mathrm{~N} / \mathrm{A}$ \\
Trial Marriage & $28 \%$ & $20 \%$ & $\mathrm{~N} / \mathrm{A}$ \\
It does not have to be a permanent & $26 \%$ & $2 \%$ & $\mathrm{~N} / \mathrm{A}$ \\
$\quad$ commitment & & & \\
Saves the cost of the wedding & $20 \%$ & $7 \%$ & $\mathrm{~N} / \mathrm{A}$ \\
A lot of marriages fail & $18 \%$ & $7 \%$ & $\mathrm{~N} / \mathrm{A}$ \\
Better relationship & $18 \%$ & $7 \%$ & $\mathrm{~N} / \mathrm{A}$ \\
Personal independence & $16 \%$ & $2 \%$ & $\mathrm{~N} / \mathrm{A}$ \\
Yes advantages of being married rather than & $45 \%$ & $42 \%$ & $63 \%$ \\
$\quad$ living together as a couple & & & \\
Better for children & $31 \%$ & $27 \%$ & $45 \%$ \\
More definite commitment & $29 \%$ & $20 \%$ & $57 \%$ \\
Financial Security & $27 \%$ & $17 \%$ & $35 \%$ \\
Legal status & $27 \%$ & $15 \%$ & $26 \%$ \\
No Social Stigma & $10 \%$ & $3 \%$ & $5 \%$ \\
Public recognition as a couple & $9 \%$ & $3 \%$ & $17 \%$ \\
The occasion of the wedding & $7 \%$ & $10 \%$ & $11 \%$ \\
N = 100\% & 97 & 59 & 65 \\
\hline
\end{tabular}

as having advantages and not the other, with cohabitees marginally preferring marriage and single people typically choosing 'living together'. ${ }^{14}$

All who acknowledged advantages of either living together or marriage were then asked about what the advantages were by additional questions allowing multiple choices from lists of possible advantages. In the case of both 'living together as a couple' and 'being married' the lists of possible advantages included an item which used the word 'commitment'. 'Does not have to be a definite commitment' seems to have been treated by single people as an equivalent advantage to 'trial marriage' and 'no legal ties'. This was not the case among cohabitees, however, who almost never picked this item, despite a majority of those cohabitees who answered choosing 'trial marriage' and 'no legal ties'.

Table 3 shows the precentages of all single, cohabiting and married people who identified particular advantages with marriage. For obvious reasons, respondents who did not see any advantages in an arrangement were not asked what those advantages were. In order not to give an inflated sense of those who picked advantages, responses are shown as a percentage of all respondents rather than all who answered. 
For married respondents, 'more definite commitment' was the main advantage. The difference between the $57 \%$ of married respondents and the $20 \%$ of cohabiting respondents who chose this item is statistically significant. More than half of married respondents thought that marriage had the advantage of being a more definite commitment and $45 \%$ thought it was 'better for children'. For single and cohabiting respondents the most chosen advantage of marriage was 'better for children' although this item was chosen by statistically significantly fewer cohabiting respondents than married respondents. ${ }^{16}$ The pattern of answers suggests that the married respondents, despite the fact that the overwhelming majority of them had previously cohabited, were more likely to distinguish marriage and cohabiting in terms of degrees of commitment than cohabitees who have not married. At the same time, it is important not to overstate this as almost half of married couples do not declare that marriage involves a more definite commitment.

Among our intensive interviews, several cohabiting respondents reflect a combination of commitment to long-term partnership and lack of definite preference for marriage or cohabitation shown by a substantial group in the survey. Many loosely link cohabitation and marriage through getting engaged then living together with a more or less specific plan of marrying. As MacRae (1993) found for many of her cohabiting respondents with children, some respondents were cohabiting because they had not yet got married. In our study, there were couples who explained that marriage was an anticipated event but not a high priority. Their reasons for planning to marry were not about commitment, which was already taken for granted, but the desire for a party, a special day, and sometimes a gesture that would please others. Most assumed that marriage would make no difference to their relationship.

Sharon and Bill Noble who were 'daft about each other' from the beginning of their relationship, quickly started to discuss both having children and plans to marry. They had been living together for about three years before Sharon became pregnant. Although they were not using contraception, the pregnancy was a shock because they started trying to have a child two years previously and had come to assume fertility problems. They cancelled their wedding because Sharon would have been eight months pregnant on the chosen date. Once they had a child, marriage seemed less important.

Sharon: I think we would like to do it but then when we think about the money. I think we would just rather get something. Like we would like to get a bigger TV. I think we would take that rather than get married. ... It doesn't matter because I think before we really wanted to get it over and done with but now that we have had [baby] we are a bit more relaxed about it now. It isn't like we are going to go anywhere noo, you know, it doesn't matter. 
Similar sentiments were expressed by other cohabiting respondents who were planning to marry. Marriage is not the point at which they commit themselves to their relationship. As Neil Martin put it:

You, you've made that commitment you know. And it's just like you're married, you know. But I think it's, that little bit more having your own, your own day, you know.

This perspective led some cohabitees to delay or abandon marriage plans because the special day could not be the way they wanted it. They couldn't afford the money or time needed or ensure relatives would co-operate with the kind of 'special day' they wanted.

Similarly, some married couples explained that the event and fact of being married was not of great importance. For example when asked about important events that have happened since leaving school Sheila Wilson said 'buying this house' and when prompted for 'anything else', suggested 'must be getting married, eh?' to which her husband Alex Wilson replied 'I don't know if that's really important'. Sheila then went on to elaborate an account of why the house was more important than the wedding:

I mean oor wedding day was a formality. I mean we knew we wanted to be the gether [together] but it was really tae satisfy everybody else, you know. We would've just went away somewhere but I think, the most important thing as far as we, as a couple are concerned and myself, is buying the house because that's something that you've worked for and it's something that's yours and naebody can take it away frae you no matter like ... I mean Alex had, well he was married before and, kinda lost everything he had. So, em, a' the time we were the gether he wisnae a hundred percent secure until such times as we actually got something of our own. That gave him a wee bit o' security.

On the other hand some couples who cohabited and then married did distinguish between cohabiting and marriage in terms of degrees of commitment. This is said quite clearly, for example, by Mark and Debbie Thorpe when they were asked why they did not simply continue to live together rather than getting married.

Debbie: Dinnae feel there's the same commitment then.

Mark: Naw. It isnae.

Debbie went on to note that her friends who lived together without being married did not make this distinction but both she and Mark reasserted that, for them, marriage was more of a commitment.

Mark: As I say, the commitment, and you say, it's commitment, and it's finally makes it that, eh, taking vows and sticking to they vows. 
That's obviously what marriage is but they [friends who choose not to marry], they obviously dinnae see it in that, in that light.

And Debbie also raised the issue of children.

Debbie: I feel it is a more of a stable basis for family as well, if you do have a family.

A strongly expressed reason for marriage among respondents concerns the issue of children and having a common family name. Lewis (1999) and Smart and Stevens (2000) have found this to be an issue which retains importance for many couples. Many of our respondents wanted to act on the view that marriage was better for children. Anne Whyte shared this view but an unexpected pregnancy meant that events did not unfold in this way. She and Colin Whyte had not begun to plan a future together when Anne became pregnant at age 20. Each still lived with their parents and Colin moved in to Anne's parents' house until they managed to get a council flat. After two years of living together, they decided to get married.

Anne: 'Cause I decided for the sake o' [child] as well, I'd rather we were married for her sake, as well. Because she's got the same name as Colin whereas I wouldn't as well you know. It's a bit o' this and that. I wanted to. Colin wanted to. So there's no much point in not. It's never made any difference on us really, no changed anything, because we knew, we would be the gether anyway.

After this reassurance about how being married was no different from living together, Anne, nevertheless, added some further remarks suggesting that marriage tidies thing up with a form of completion or closure confirming a permanent arrangement.

Anne: So we'd got our house, got car, got jobs, we had [child], we had really everything, so it was just a case of sorting oursels and just getting married.... We had lived the gether anyway for two years, so we ken what each other was like and everything. And if it was a case o' that we were just no gonna make it, then we wouldnae have bothered I suppose.

As noted in the introduction, whether couples enter into cohabitation as the beginning of a permanent partnership, as a way of testing out the suitability of a relationship for such a partnership, or with little thought for the future, a range of attitudes to marriage is possible. The views of marriage held by our respondents generally seem to be either neutral or positive seeing marriage as 'better for children' or a more definite commitment. The numerical balance was in the neutral camp. Opinions about marriage and cohabitation often 
lacked vehemence. Only one couple among the interviewed cohabitees, Stuart Sheridan and Karen Groves, had specific negative things to say about marriage. Stuart Sheridan was a self-employed tradesman who has previously been married and has recently started to see more of his child from this marriage. He and Karen lived together for six years. Both saw it as a permanent arrangement from the beginning. They had one child. The couple were in a great deal of debt, most of it generated by Stuart and much of this was a legacy of his previous marriage. This led to a defensive sense of the importance of financial independence. Karen went reluctantly back to her paid employment when their child was only ten weeks old in order to ensure that she would keep her job and her sense of independence. Marriage was viewed negatively as legally obliterating financial independence. But underlying the concern to maintain financial independence was also the unspoken assumption that their relationship might break down. What was actually said was that when things do break down then marriage makes it much worse.

Karen: After seeing and hearing, hearing about the split up with his exwife, financially it's easier to keep separated, in that sense of the word like.

Stuart: Aye it's easier to keep like we are rather than being married. You get married and money becomes, if you separate money becomes a right mess.

Karen: Like for example when him and his ex-wife split up he was, when I first met him he was paying thousands of pounds of debt for stuff that she had with her. And its like uhh. Just things like that ken. Best to keep it separate to a certain degree I think. We've not even got a joint bank account though and we keep to that, but we do - people say that you mustn't live together if you don't have a joint bank account but that's rubbish.

\section{Discussion}

The study reported here gives insight into attitudes to cohabiting and commitment to long-term or life-time partnering among heterosexual couples aged 20-29, a key age group in terms of ideals and practices of partnership formation. It provides new evidence that there is no simple relationship between cohabiting and 'lack of commitment'. This does not support the pessimistic view that a growth in cohabitation reflects selfish unwillingness to make significant investments in family relationships. The majority of couples in this study chose to describe how they began living together as entering a permanent arrangement. Interviews found most cohabiting couples stressing and itemising their commitment to each other. A minority described the beginning of living with a partner as a bet hedging 'try and see' strategy. For most this meant trying to see whether this relationship was going to become 
a permanent partnership rather than entering into an acknowledged temporary and casual arrangement. However, cohabitation did have connotations of less permanence for many in the age group but this idea was strongly repudiated by most, although not all, cohabitees.

Despite the fact that a permanent relationship is the assessment most young people give of the starting point of their cohabitation, this does not mean that setting up home together was a planned and anticipated event. The majority of our sample claimed to lack any prior plan concerning the timing of setting up home together and, among those with children, this lack of planning extends to the timing of their first child. Young people with well developed plans for employment and housing denied planning their personal life, suggesting cultural taboos against some forms of overt planning persist, making it difficult to unravel interaction between planning in other domains and personal life (Anderson et al., 2002). The act of moving in together and marriage as a 'special day' or 'big day' offer very different opportunities for socially acceptable planning and expressions of spontaneous versus staged romance. While a stated intention to marry at some stage preceded living together for many, a sense of commitment was often generated in a context of no specific plans for the future of the relationship and no ceremony at the point of moving in together.

Over half of respondents demonstrate the blurring of marriage and cohabitation through their lack of strong views about the relative advantages and disadvantages of each. It seems that they did not want to make a clear distinction between the two forms of partnership. Very few cohabitees claimed that living together outside of marriage is something different to and better than marriage and the majority repudiate the notion that it is a lesser commitment. Nobody we interviewed who had been successfully cohabiting for some time explicitly talked of it as a temporary arrangement. This is a judgement that seems more likely to be passed in retrospect on past failures.

On the other hand, both the survey and the intensive interviews show that a significant minority continue to emphasise the greater commitment of marriage. A significant minority of single people, over half of married couples, and a fifth of cohabiting couples declared on the survey that they saw marriage as a greater commitment than cohabitation. However, endorsements of marriage were relatively low key. Interviewees who felt strongly that marriage is more of a commitment, acknowledged that others do things differently and do not see it this way. As Lewis (2001) has suggested, there was little sense of any clear moral distinction.

It is interesting to try and establish which respondents emphasised the easier exit of cohabitation rather than the greater commitment of marriage as a desirable distinction. In interviews, young men and those who perceived their relationships as at a high risk of breakdown made a particular point in stressing the advantages of easier exit. In the survey, a more substantial minority of younger respondents, and particularly younger men, described entering into their cohabiting relationships in terms of 'try and see'. The higher inci- 
dence of a 'try and see' approach among younger respondents may mean that acknowledging the prospect of failure and seeking easy exit is becoming more socially acceptable. This need not signal a profound change in ideals, but simply that it is more acceptable to acknowledge doubts, uncertainties and hence the need for trial and error. This interpretation is consistent with the seemingly contradictory account of the likes of Bill Noble who declared his starting point as very in-love with his partner and anticipating a long-term arrangement yet on a 'try and see' basis. Conventions of masculinity may also modify the vocabulary of young men. A persistent version of youthful masculinity that denigrates prematurely 'settling down' may encourage a 'try and see' vocabulary among younger men, albeit that explicit talk of retaining 'freedom' was only common among some single male respondents (Jamieson et al., forthcoming). In-depth interviews suggest caution about the type of fit that should be assumed between public descriptions of 'try and see' and private hopes.

Sometimes the use of 'try and see' among younger respondents reflected higher than average risks. Starting a cohabiting relationship at a younger than average age and/or as a result of a pregnancy are objectively risky ventures. The statistics may not be well known, but a sense of the possibility that 'things might not work out' was clearly recognised by respondents like Douglas Syme. In other words, our findings contain examples that are entirely consistent with Smart's and Stevens' (2001) suggestion that some respondents are making rational choices when they view marriage as 'too risky'. Youthful marriage has largely been replaced by youthful cohabitation and relationships entered as teenagers remain more likely to end in separation whether they involve subsequent marriage or not. Similarly, pregnancy-provoked marriage has largely been replaced by pregnancy-provoked cohabitation. While pregnancyprovoked cohabitation can be an outcome for couples of a range of ages, the younger the couple experiencing an unplanned pregnancy, the more probable it is that the pregnancy occurred before a sense of consolidation and planned future as a couple. Understandably, those who respond to an unexpected pregnancy by living together despite no previously agreed future together are very likely to talk of setting up home together in terms of 'try and see'. While an entirely pregnancy-provoked partnership was always perceived by those experiencing it as involving risk, experience of other factors that are objectively associated with relationship breakdown, such as low income and unemployment, were rarely talked of in this way. While on average cohabiting couples are objectively more at risk than married couples, because of lower incomes and more uncertain unemployment, only exceptionally were economic circumstances seen as making marriage 'too risky'.

Unexpected pregnancy does not always mean trying to get on as a couple in circumstances of previous lack of commitment as it often occurs in a context of an established relationship. In such circumstances, the pregnancy is not a factor causing the relationship to be viewed as a risky venture and, indeed, 
there is no such subjective sense of risk. Yet our intensive interviews suggest that among couples who are already cohabiting and committed, an unplanned pregnancy might be more likely to delay marriage than to hasten it. With respect to the British Household Panel Survey, John Ermisch and Marco Francesconi (2000) note that once cohabiting couples have children they are just as likely to split up as childless couples and less likely to marry. One possible explanation that they suggest is that those who felt they should marry when they started a family did so before children were born. This may be true for many but not all. Our and other qualitative studies (McRae, 1993) identify consolidated couples who did expect to have a child together at some point and planned to marry first but the timing became out of sequence. Some still planned to marry but have not yet 'got round to it'. It is not clear if or why such couples should be more vulnerable to subsequent dissolution than their equivalents who implemented plans to marry in time. The main reasons cited for delay in marriage by these would-be-married cohabitees are that the wedding now competes for resources that have been made more scarce and with other needs that have been heightened by the presence of a child. It is likely that those who fail to achieve plans to marry are the least well resourced and economic insecurity is an objective risk factor known to make couples more vulnerable to dissolution.

Exceptionally, economic insecurity in itself can be a perceived as a reason for preferring cohabitation over marriage. It is possible for cohabitees, and particularly those with previous failed marriages, to feel that the legal and financial ties of marriage might bring more losses than gains. The example of Stuart and Karen is an extreme case in which prior debts and a strong sense of financial insecurity encouraged the absence of legal ties. For them cohabitation was a form of insurance against the possibility of one sucking the other down to new levels of economic insecurity. However, Stuart and Karen were unusual among cohabitees in making a virtue of the easier exit from cohabitation than marriage. More cohabitees were at pains to stress the opposite, by emphasising that marriage would make no difference to their relationship and itemising practical and material factors binding them together, running a household together, buying a house, planning a child, bringing up a child together, which, in their view, were more important than a marriage certificate.

The paper shows clearly the value of in-depth interviews if we wish to go beyond respondents' choice of acceptable vocabulary for describing their relationship to the deeper meaning of relationships for respondents. Whatever people say about the beginning of their relationship, relationships are a process and people's views of cohabitation and marriage change over time. For example, couples who described the start of their relationship in terms of 'try and see', often then planned to marry and sometimes put plans on hold, as was the case with Sharon and Bill Noble. Once established, their sense of having a long-term relationship was apparently unaltered by the objective strains of unemployment, shifts in income and the demands of an unexpected 
child, although getting married became less important. While asking about different time periods in a survey can give some insight into process, in-depth interviews undoubtedly offer more scope for understanding how processes unfold. Interviews allowed people to tell a story of growing or sometimes faltering commitment. Combining in-depth interviews and survey material also illustrates how responses to surveys conceal variations confounding similar and different answers. For example, although interviews typically confirmed a desire and expectation of permanence, they also picked up acknowledgements of earlier doubts among the those who declared their relationship as 'a permanent arrangement' from the beginning and desires for permanence among those who declared their arrangement as one of 'try and see' at the outset.

In earlier discussion of the literature, it was noted that a number of authors predicted a shift from cohabitation as a prelude to marriage to an alternative to marriage. Authors seem to suggest a blurring of cohabitation and marriage, a loss of any sense of significant difference between them among new generations making their first partnership decisions (Haskey, 2001; Kiernan, 1999; Lewis, 2001, 1999a, 1999b; Prinz, 1995; Shaw and Haskey, 1999). At the same time, some of this literature (see also Ermisch 2000 Kravdal 1999, Smart and Stevens, 2000) continues to stress the social significance of the distinction between marriage and cohabitation, suggesting that cohabitation has come to be seen as a half-way house, a try and see, 'bet hedging' strategy that is only part-way to the full commitment of marriage. Support is found in this study for both of these apparently contradictory views. This is possible both because of variation within the sample, neither cohabitation nor marriage meant the same thing for everybody, and because people sometimes seem to hold both these contradictory views. While many young people now think it makes little difference whether they marry or not, cohabitation is sometimes maintained as the default position, even when marriage is acknowledge as more desirable. This is because circumstances are seen as working against marriage, sometimes by making the relationship too risky but more commonly simply by creating obstacles to the ideal wedding event.

University of Edinburgh

Received 18 October 2001 Finally accepted 12 April 2002

\section{Notes}

1 The study is an Economic and Social Research Council funded project, R 000238020, 'Telling the Future', principal investigators Michael Anderson, Frank Bechhofer, David McCrone, and Lynn Jamieson, researchers Yaojun Li and Robert Stewart. The survey questionnaires were designed by the research team and the fieldwork carried out by Public Attitude Surveys (PAS). We are grateful to the Institute for Social and Economic Research (ISER) at the University of Essex, and especially Dr Heather Laurie, for helping commission and pilot the surveys, data checking and cleaning, and carrying out occupational coding. Telling the Future was 
designed to complement a study of adults aged 30-70, 'Decade of Change', (conceived and designed by the principal investigators Michael Anderson, Frank Bechhofer and David McCrone, funded by an ESRC grant (R 000236922) and carried out with the help of the researchers Yaojun, Li and Robert Stewart) which was following up a sample of respondents from the ten year earlier ESRC funded 'Social Change and Economic Life Initiative'. This paper, like all those arising from this project, is the product of a collegiate form of working in which the fieldwork, the analysis and the drafts of the papers have been discussed by the entire research team throughout. The first author has been responsible for initially drafting this paper, carrying out analyses and revisions and seeing it into print; the second author has also contributed to analysis; the names of the other authors are in random order.

2 The postal districts comprised the travel to work area of Kirkcaldy district, a mainly urban area of small and medium sized towns.

3 Couples were identified as such because they were 'living with a partner'. While this approach to identifying couples theoretically could have included same-sex partners, none emerged from the sampling process.

4 Sixteen partners were older, five were younger and in one case the age was not recorded.

5 As in other studies, cohabiting respondents have higher rates of unemployment, lower average educational qualifications and lower average incomes than married respondents. In our sample, $24 \%$ of cohabiting men and $23 \%$ of cohabiting women were unemployed and an additional $12 \%$ of males and $26 \%$ of females were out of the labour force because of caring responsibilities or ill health. This compares with unemployment levels of $3 \%$ and $13 \%$ and non-employment levels of $3 \%$ and $23 \%$ among our married male and female respondents. $27 \%$ of cohabiting men and $26 \%$ of cohabiting women had at least Higher Grade/A level qualifications compared with $35 \%$ of married men and $36 \%$ of married women. There is no difference in terms of the proportion of men with no or vocational qualifications, $42 \%$, but $50 \%$ of cohabiting women have no or vocational qualifications compared with $38 \%$ of married women. Differences in terms of household income between cohabiting and married respondents are as follows (net household income after deductions and benefits). For both cohabiting men and cohabiting women, the median lies in the $£ 12,480-14,559$ band. For both married men and women it fell in the $£ 18,720-20,799$ band.

6 Our intensive interview respondents are more socially mixed than Lewis's qualitative sample of 17 married and 12 cohabiting affluent young couples with children. They are younger and have been cohabiting for shorter periods than both Lewis's and Smart and Stevens's samples and, unlike these samples include childless couples. The majority of Lewis's sample were aged between 30 and 45 years old and had been cohabiting for over ten years and the majority of Smart and Stevens's sample had cohabited for over two years. They are also differ from Smart and Stevens sample in that this is a sample of couples who are cohabiting rather than individuals who have cohabited.

7 Details are sometimes changed slightly or made vague in order to protect confidentiality. For brevity and ease of reading, quotations are edited to remove the interviewer's encouraging utterances 'yeah' and 'right' which pepper the flow of conversation but add nothing to the meaning. Otherwise quotations are verbatim. Inaudible parts are shown (... ?) and omissions are indicated by three full stops.... Any explanatory comments added after the interview are shown in square brackets [ ].

8 This table is based on couples in which both partners were participants in the survey and includes partners who fall outside of the 20-29 age range.

9 The differences in the table that are statistically significant are generally between those who married never having cohabited and those who married after cohabitation. This is true of answers for the following: 'We fell in love ...', 'The time had come ..., 'Rented accommodation ...', 'I was at a suitable point ....'

10 'We are interested in why you and your partner got married or set up home together when you did. Would you please tick those things which were important in influencing the point in your life when you first set up home together'. Only respondents and their partners aged 20-29 are included in this table; older and younger partners have been excluded. 
11 Seven cases of respondents age 20-29 who were cohabiting following a previous marriage have been excluded. They have the potential to be sufficiently different to merit their own column within the table but the numbers are too small to justify the calculation of percentages.

12 Married couples were not asked whether there were advantages of living together over marriage.

13 Among single respondents $29 \%$ of men answered yes to both questions and $25 \%$ answered no to both questions; $38 \%$ of women answered yes to both questions and $23 \%$ answered no to both questions. Among cohabiting respondents $28 \%$ of men answered yes to both questions and $31 \%$ of men answered no to both questions but there was a more marked differences among women with $18 \%$ answering yes to both questions and $41 \%$ answering no to both questions.

$1423 \%$ of single people thought there were advantages of living together over marriage and not vice versa and $6 \%$ thought there were advantages of marriage over living together and not vice versa. The equivalent figures for cohabitees were $14 \%$ and $23 \%$. Of all who were asked $10 \%$ said did not know.

15 Single include those who have previously cohabited but exclude the previously married as they have a rather different pattern of responses but numbers are too small to justify a separate column in the table. Similarly cohabiting excludes the previously married.

16 There were some gender differences in choice of advantage with women stressing 'no legal ties' as an advantage of living together rather more than men. With respect to the advantages of marriage, women stressed financial security, 'more definite commitment' and legal status more than men.

\section{References}

Anderson, M., Bechhofer, F., Jamieson, L., McCrone, D., Li, Y. and Stewart, R., (2002), 'Confidence amid Uncertainty: Ambitions and Plans in a Sample of Young Adults', Sociological Research Online, vol. 6, no. 4, http://www.socresonline.org.uk/6/4/anderson.html

Ermisch, J., (2000), 'Personal relationships and marriage expectations: evidence from the 1998 British Household Panel Study', Working Paper 2000-27, Institute for Social and Economic Research.

Ermisch, J. and Francesconi, M., (2000), 'Patterns of household and family formation', in Berthoud, R. and Gershuny, J. (eds) Seven Years in the Lives of British Families: Evidence on the dynamics of social change from the British Household Panel Survey, London: The Policy Press.

Giddens, Anthony, (1991), Modernity and Self-Identity: Self and Society in the Late Modern Age, Cambridge: Polity Press.

Giddens, Anthony, (1992), The Transformation of Intimacy: Sexuality, Love and Eroticism in Modern Societies, Cambridge: Polity Press.

Haskey, John, (2001), 'Cohabitation in Great Britain: past, present and future trends and attitudes', Population Trends 103: 4-25.

Haskey, John, (1999), 'Cohabitational and marital histories of adults in Great Britain', Population Trends 96: 13-23.

Jamieson, L., Stewart, R., Li, Y., Anderson, M., Bechhofer, F. and McCrone, D., (forthcoming), 'Single, twenty something and seeking?' in Allan, G. and Jones, G., Time and the Life Course: Age, Generation and Social Change, London: Palgrave.

Jamieson, L., (1999), 'Intimacy transformed: a critical look at the pure relationship', Sociology, 33: 477-494.

Jamieson, L., (1998), Intimacy: Personal Relationships in Modern Societies, Cambridge \& Malden, MA: Polity Press.

Kiernan, Kathleen, (1999), 'Cohabitation in Western Europe', Population Trends, 96: 25-32. 
Kravdal, Oystein, (1999), 'Does marriage require a stronger economic underpinning than informal cohabitation', Population Studies, 53: 63-80.

Lewis, Jane, (2001), The End of Marriage: Individualism and Intimate, Relations Cheltenham: Edward Elgar Publishing.

Lewis, Jane, (1999a), Marriage, Cohabitation and the Law: Individualism and Obligation, London: Lord Chancellor's Department, Research Series no1/99.

Lewis, Jane with Datta, Jessica and Sarre, Sophie, (1999b), Individualism and Commitment in Marriage and Cohabitation, London: Lord Chancellor's Department Research Series no 8/99.

Manting, Dorien, (1996), 'The changing meaning of cohabitation and marriage', European Sociological Review, 121: 53-65.

McRae, Susan, (1993), Cohabiting Mothers: Changing Mothers and Motherhood? London: Policy Studies Institute.

Prinz, Christopher, (1995), Cohabiting, Married or Single: Portraying, Analyzing and Modeling New Living Arrangements in the Changing Societies of Europe Aldershot: Avebury.

Shaw, Chris and Haskey, John, (1999), 'New estimates and projections of the population cohabiting in England and Wales', Population Trends, 95: 7-17.

Smart, Carol and Stevens, Pippa, (2000), Cohabitation Breakdown, London: published for the Joseph Rowntree Foundation by the Family Policy Centre. 